\title{
Knowledge-Based Economy as a Basis for the Long-Term Strategy of the Development of the Society
}

\author{
Elena Pilipenko \\ Kurgan Division of the Institute of Economics, Ural Branch of the Russian Academy of Sciences, \\ Kurgan, Russia \\ Email: pilipenkoev@bk.ru
}

Received 20 July 2015; accepted 14 August 2015; published 17 August 2015

Copyright (C) 2015 by author and Scientific Research Publishing Inc.

This work is licensed under the Creative Commons Attribution International License (CC BY). http://creativecommons.org/licenses/by/4.0/

C) (i) Open Access

\begin{abstract}
This article is devoted to the research of theoretical and methodological aspects of economy of knowledge formation. The emphasis is laid on the evolution of knowledge as the main reason of any changes which take place in the society. Scientific knowledge is considered as the key resource of creating social wealth; and the process of its production-as an indissoluble processing chain which consists of spiritual, informative and material production. Such approach brings about the necessity of drastic review of the whole system of economic categories and grounds in it models, methods, criteria and exponents. Authorial conception of economy of knowledge is suggested. It is based on three main principles: 1) the unity of economic field; 2) preferred development of spiritual production; 3 ) accordance of controlling mechanism and effectiveness exponents to the peculiarities of goods of any production.
\end{abstract}

\section{Keywords}

Society, Economy, System, Knowledge-Based Economy, Mental Production

\section{Introduction}

Today we are intensively searching for a new paradigm of the social development which is able to explain adequately the ongoing events and proposes the acceptable concept of the future world order. This process is of principal importance, because every economy is not an end goal, but a more or less efficient instrument for the implementation of the global goal of any society-guaranteeing the continuous process of satisfying the growing needs of the present and the future generations. 
The degree of efficiency of an economic mechanism will fully depend on the degree of consistency of true (not manifested) goals of the social development with the selected methods of their implementation. In our point of view, today's crisis is related to the fact that the methods of implementation of the stated goal (satisfying the growing needs of the present and the future generations) exclude the very possibility of achieving it. It is the explanation for such a tense search of the new economic mechanisms and instruments being relevant to the true goals of the social development. Let us consider which of the existing concepts of the social development will form the best basis for its implementation.

\section{Literary Review}

The concept of the post-industrial society was mostly widespread in the second half of the XX century. In fact, this concept presents the development of the theories of the "industrial society" (R. Aron) and the "stages of the economic growth" (W. Rostow) popular in the 60-s of the last century. The main principles of the theory of the post-industrialism are described in the works of D. Bell, H. Kahn, Z. Brzezinsky, A. Toffler, J. Fourastié and others. In general, the concept of the "post-industrial society" claims to be a general sociological theory of the upward tendency of the mankind. The post-industrial society is set against the pre-industrial and the industrial ones in terms of the following parameters: the main production resource; the type of production activity; the character of basic technologies [1] (Table 1).

Still, in spite of the numerous studies, the true reason for the ongoing changes, in our opinion, was not found out, because the principal attention was paid to the description of the external characteristics of each stage of the social development in prejudice of the description of the driving forces, the internal logic and the contradictions of this process. We agree with V. Inozemtsev calling the doctrine of the post-industrialism "too objectivist". Paying much attention to the objective factors-technique and technology (the so-called technological determinism) in prejudice of the subjective factors did not allow the supporters of the post-industrialism seeing the essence of the changes and, thus, finding an efficient mechanism for influencing them. In fact, the consequence was considered to be the cause. All the changes that are described as a reflection of the theory of the post-industrialism - the transfer to the information as the main production resource, the substitution of the labour-intensive technologies by the research-intensive ones, the change in the character of human interaction in the production process etc.- -are actually the result of both evolutionary and revolutionary changes in the mental, intellectual human nature, the human advance in the process of understanding the world (the nature) from the religious faiths to the theoretical scientific knowledge. Taking all these facts into account, we suppose that Table 1 should look as follows (Table 2).

Table 1. Evolution of the human society.

\begin{tabular}{ccc}
\hline & Pre-industrial & Industrial \\
\hline The main production resource & Raw materials & Energy \\
The type of production activities & Extraction & Production \\
The character of basic technologies & Labour-intensive & Capital-intensive \\
The character of interaction & Man with nature & Man with the transformed nature \\
\hline
\end{tabular}

Table 2. Evolution of the human society.

\begin{tabular}{|c|c|c|c|}
\hline & $\begin{array}{l}\text { Predominance of the } \\
\text { pre-scientific knowledge and } \\
\text { faiths }\end{array}$ & $\begin{array}{l}\text { Combination of the empiric and } \\
\text { theoretical scientific knowledge }\end{array}$ & $\begin{array}{c}\text { Predominance of the } \\
\text { theoretical scientific } \\
\text { knowledge }\end{array}$ \\
\hline The main production resource & Raw materials & Energy & Knowledge \\
\hline The type of production activities & Extraction & Processing & Production \\
\hline The character of basic technologies & Labour-intensive & Capital-intensive & Research-intensive \\
\hline The character of interaction & Man with nature & $\begin{array}{c}\text { Man with nature and artificial } \\
\text { environment }\end{array}$ & $\begin{array}{l}\text { Man with artificial } \\
\text { environment }\end{array}$ \\
\hline The type of the social structure & Pre-industrial & Industrial & Knowledge society \\
\hline
\end{tabular}


The emphasis made in Table 2 on the evolution of the knowledge as the main reason for any changes going in the society clearly identifies the main character being at the same time the reason and the result of these changes - the human being. This makes us look differently at the sphere of the mental production considering it to be the key and decisive area in all social and economic process, and concentrate our attention and efforts on studying the processes and regularities characteristic of this field.

In the 80-s of the previous century under the influence and as a result of the new stage of the technological revolution, the theory of the post-industrialism transformed into the concept of the information society without changing its principal social and economic content. The notion of the "information society" was introduced in the beginning of the 60-s almost at the same time in the USA and in Japan by F. Machlup and T. Umesao. Afterwards the significant contribution to the development of this concept was made by M. Porat, Y. Masuda, T. Stonier, R. Katz and many others. Within the frames of this concept the production, dissemination and consumption of the information are viewed as the predominant sphere of the economic activity of the society.

This concept can claim for the status of the new social development paradigm even to a lesser extent than the concept of the post-industrial society due to the whole set of reasons; in the first instance, due to an obviously inadequate (exaggerated) assessment of the level of independence of the information in the production process and in the social life. The role of the information as a resource, especially in the modern research-intensive production, is difficult to overestimate. All studies in this field, that is the studies of information as a specific resource, are relevant, important and useful.

Still, we cannot forget that the information becomes the knowledge, which is a true determinative factor of the social life, only in the human mind. Therefore, before we're able to create an artificial intelligence comparable to the human brain in terms of its parameters, we cannot speak of electronic devices as capable of creating the new knowledge from the information received or processed by them. Probably it is more correct to say that the electronic (or any other) devices speed up and facilitate the processing the information, and thus significantly facilitate the process of creating the new knowledge by the person. Nevertheless, in any case the information has always been and, apparently, will be a resource subordinate to the man for a rather long time (if not forever); the efficiency of this resource is fully dependent on the subjective characteristics and properties of the personality. Thus, in our point of view, there are no grounds for considering the information to be an independent, self-sustainable and systemically important factor of the social life. This independent, self-sustainable and systemically important factor is the human creative activity with the information being one of its resources and products.

In general, the concept of the information society has significantly enriched the ideas of the modern stage of the social progress, but in our opinion further it is more productive to consider the information as a product of the mental production existing within its framework and in accordance with its laws. Thus, studying of the sphere of the mental production itself becomes of primary importance.

In the recent years the concept of the knowledge-based economy and the knowledge society has been predominant in the economic science, engrossing the minds of the researchers and the politicians. In the scientific literature there is a widespread view of the knowledge-based economy as a "new" and "unknown" economy; one the one hand this opinion is well-reasoned. Still, we suppose that it would be more correct to consider the knowledge-based economy not as an inexplicable phenomenon with unknown backgrounds, but as a logical step of the evolutionary development of the productive forces resulting from the transfer of the scientific knowledge acquired by the mankind to the new quality level.

The source of wealth in the knowledge-based economy is the activity developing human capacities, which is the "labour" of self-comprehension being performed by the "individuals" independently and altogether in the process of an all-round exchange. The development of the human capacities is, at the same time, the aim of the activity and the activity itself. There is no difference between the goal and an incomplete pursuit of this goal. We are facing the fundamental revolution: this is not a person serving the development of the production, but the production serving the human development and self-comprehension [2].

\section{Method and Model}

How these principles can be practically implemented in the economic activity?

We're not aspiring to propose a universal and final solution to the problem, we still offer our variant (Figure 1) presenting the concept of the knowledge-based economy and founded on the following principal moments [3]:

- the integrated economic field;

- the priority set to the development of the mental production; 


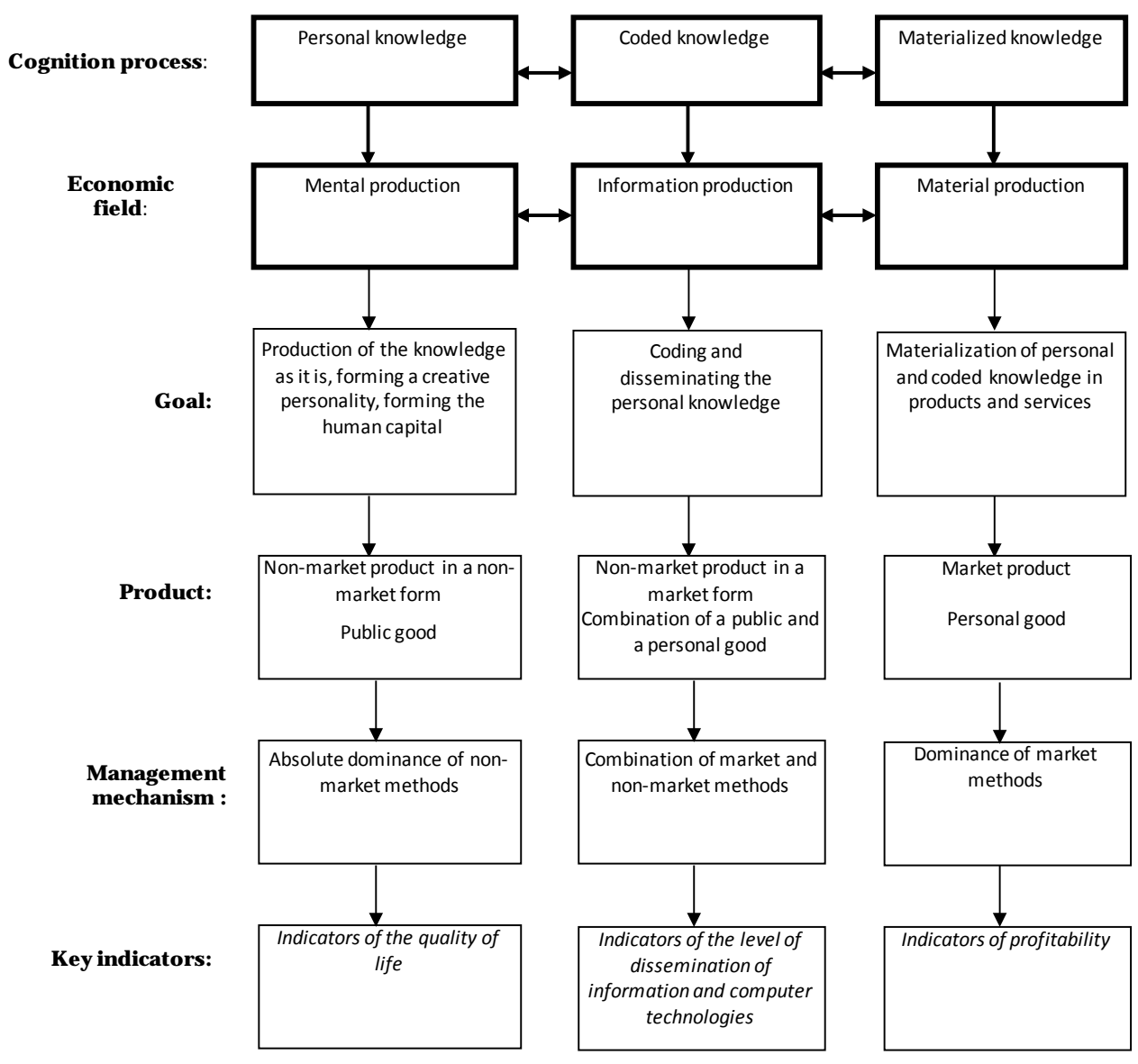

Figure 1. System of categories of the knowledge-based economy.

- the conformity of the management mechanism and the performance indicators to the specific features of a product of each type of production. This allows taking the sphere of the mental production away from the influence of the market that will contribute to increasing the efficiency of the development of each type of production in particular, and the system as a whole.

The proposed model is a reflection of the objective reality-the cognition process. We suppose that we can claim at full certainty that the process of cognition always starts in the mind of a person, and only the person influences what form will have the results of his or her cognitive activities—a note, a book, a material object—or they will stay his or her thought, an idea that will never leave his or her mind. A principally important fact for understanding the mechanisms of functioning of the integrated economic field is that neither of the elements of this chain (mental—information-material production) can exist without the others; their existence and development are interdependent. The total of the moral, information and material productions forms an integrated technological chain of production and using the knowledge: the process of the knowledge production starts in the mental production from forming the ideal (personal) knowledge, continues in the information production in the form of coding and disseminating the knowledge and is finalized by its materialization in the material production.

On the one hand, both material and information production are presenting the ideal knowledge acquired in the mental production in other forms (coded and materialized respectively). In other words, the aim of the information and the material production is the processing of the knowledge acquired in the mental production. An interruption or a non-efficient functioning of the mental production automatically result in the slowdown and the stoppage of the information and the material productions, because they lose both the subject and the instrument of labour.

On the other hand, even the personal knowledge being unique in terms of the possibilities of influencing the real life of a person and the society is lost for the society and the social progress without being materialized. In 
fact that materialization of the knowledge is one of the most important conditions for their existence.

Still, the material production is always secondary to the mental production, because it only materializes the concepts and ideas created earlier in the process of the mental production. It makes obvious the system of interaction and subordination in the integrated economic field: the source and the foundation of the social wealth is the mental production. The material production only materializes the ideas created in the mental production in a more or less successful way. The information production is a link between the mental and the material production and combines the features of both of them.

It is easy to notice that the structure of functioning of the knowledge-based economy presented in Figure 1 does not have either national, or social features or preferences: it is not related strictly to the capitalist or the social mode of production; it is not an "American", "Islamic", "Russian" or any other national, territorial or religious model. Being the reflection of the objective reality—the process of cognition-it has a universal character. The main requirement set by the knowledge society to the knowledge-based economy as a mechanism of achieving its goals is to guarantee the priority development of the mental production in the integrated economic field. In the knowledge society (and economy) it is necessary to develop such mechanism in which the material production will occupy not the predominant position not typical for it, but the natural closing position (as clearly seen from Figure 1) bearing only the function of materializing the ideas created in the course of the mental production. It is a very complex process requiring in many cases the complete reconstruction of the system of social and economic relations, and different societies will implement it differently basing on the institutions they have already established and creating those having never been typical for them.

The necessity (or to be more precise the objective regularity) of the radical changes in the social (and, as a consequence, in the economic order) can be easily explained-till date the human being as a personality (more specifically — as a creative personality) have never been an objective of the social development, and has always been treated as a more or less necessary means of achieving the goals in the sphere of material production. But this was the centuries-long evolution of the material production and the maximum possible development of technologies that resulted in the understanding of the necessity of changing the goals and the directions of the social development and considering the person as a single creator of the knowledge as the only one truly inexhaustible resource of the social and economic development to be the main priority and the most important factor of the development. Such perception of the knowledge-based economy provides us with a simple orienting point in the complex terminological debates about defining its essence and notion, and this criterion is the aim of the economic development.

Let us now apply this criterion to a particular situation to answer the question: is the "innovative economy" the same thing as the "knowledge-based economy"? In the modern scientific literature authors often do not differentiate between these notions, and the terms "knowledge-based economy" and "innovative economy" are used as synonyms ${ }^{1}$. Meanwhile, these are principally different phenomena in terms of the worldview. What is the aim of the "innovative" economy? It is absolutely the same to the aim of the "non-innovative" one (being substituted by the "innovative")—increasing the profit gained. Innovations are not more than a means of obtaining less expensive raw products and materials (including substituting the vanishing natural resources by the artificial ones), less expensive and "problematic" labour force (that means substituting the man with his growing social needs by machines in the production process) etc. That is why the countries having made a significant process in building this kind of innovative economics faced the escalation of the social and economic crises despite of their expected decline. And this is no surprise, because the core of the economic system has not been changed - the material production still predominates over the mental one, the human existence and development are still viewed not as an absolute value and the main aim of the society, but only from the point of view of their utility to the material production. In terms of this criterion (the aim) the innovative economy is just another modification of what we call the "traditional" economy, and due to this fact it is not able to "blow up" the system that generated it (Figure 2).

But if we follow this criterion (the aim of the economic development) we might come to the conclusion that today there are no grounds for speaking about the knowledge-based economy as an accomplished fact. And we suppose this to be true. We can speak of the growing trend, and it is necessary to study the driving forces of this process and build up efficient (consistent and non-antagonist) relations with them in the new economic field. We

\footnotetext{
${ }^{1}$ For example: "In the context of this work from the very beginning we should underline that the terms 'innovative economy' 'new economy' 'knowledge economy' and 'knowledge-based economy' are used here as synonyms without differentiating between the linguistic, etymological and contextual accents of each of the terms" ([4], p. 116).
} 


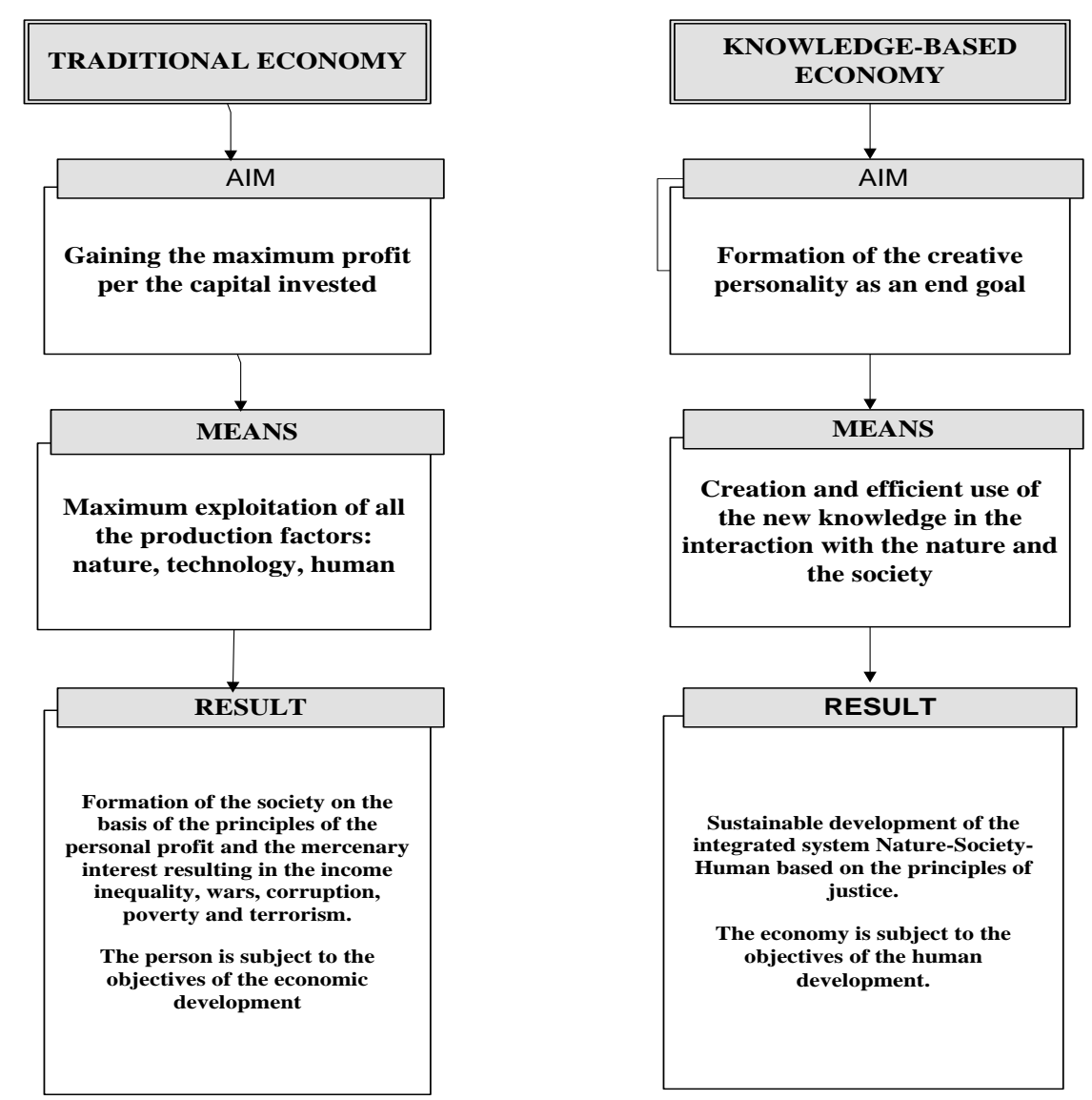

Figure 2. Differences between the knowledge-based economy and the traditional economy.

should also take as a premise the fact that the formation of the knowledge-based economy is an objective and an irreversible process, because the transfer of the knowledge acquired by the mankind to the new quality level is an accomplished fact.

\section{Conclusion}

The formation of the knowledge-based economy is a time-consuming and a painful process (because it is related to the inevitable process of breaking social stereotypes) being (at best) in the initial phase. It is clear that this process will be characterized by the specific features for each country that will be determined by the peculiarities of the production structure, the innovative system and the mentality of the population. But already today all strategic and tactical decisions (both economic and political) should conform to its requirements. Of course, for the moment it is impossible to define the whole "range" of these requirements, but the principal one is obvious - the development of the person should be considered as the actual aim and the criterion of the social progress. The problems and prospects of the formation of the knowledge-based economy and the knowledge society in Russia will, finally, depend on the level of success in solving this problem.

\section{Acknowledgements}

The article is prepared at the expense of the integrative basic research program of Ural Branch of the Russian Academy of Science "Priority modernization guidelines of local production systems under conditions of joining of Russia to WTO”, project No.12-И-7-2010.

\section{References}

[1] Inozemtsev, V.L. (2000) Modern Post-Industrial Society: Nature, Contradictions, Prospects. Logos. 
[2] Gorts, A. (2010) Non-Material. Knowledge, Value and Capital. Publishing House of the State University, 208.

[3] Pilipenko, E., Efimenkov, V., Tatarkin, A. and Grinyk, K. (2008) Dialectics of the Material and Mental Production in the Knowledge-Based Economy. Institute of Economics of the Ural Branch of the Russian Academy of Sciences, Shadrinski Dom Pechati (Shadrinsk Publishing House), Shadrinsk, 295.

[4] Mindeli, L.A. and Pipiya, L.K. (2007) Conceptual Aspects of Forming the Economy of Knowledge Problematics. Points of Forecasting No. 3. 